\title{
Papillomaviruses in Multiple Tumours of Twin Goats
}

\author{
Paola Simeone ${ }^{\mathrm{a}, \uparrow}$, Mariarita Romanucci ${ }^{\mathrm{b}, \uparrow}$, Consuelo Rizzo ${ }^{\mathrm{a}}$, Rossella Brandi ${ }^{\mathrm{a}}$, Daniela Malatesta ${ }^{\mathrm{b}}$, \\ Giovanni Di Guardo ${ }^{\mathrm{b}}$, Laura Bongiovanni ${ }^{\mathrm{b}}$, Leonardo Della Salda ${ }^{\ddagger, \mathrm{b}}$ and Aldo Venuti ${ }^{*}, \mathrm{a}, \mathrm{a}$
}

\author{
${ }^{a}$ Regina Elena Cancer Institute, Laboratory of Virology, Via delle Messi d'Oro 156, 00158 Rome, Italy \\ ${ }^{b}$ Department of Comparative Biomedical Science, Faculty of Veterinary Medicine, University of Teramo, Piazza A. Mo- \\ ro 45, 64100 Teramo, Italy
}

\begin{abstract}
In situ hybridisation, polymerase chain reaction as well as L1 antigen immunolabelling indicated the presence of Papillomavirus in tumour samples of twin goats. These findings suggest that caprine PVs may play a role in cutaneous and ocular tumour development, similarly to what has been suggested for humans.
\end{abstract}

Keywords: Papillomavirus, goat tumour, L1, RCA, squamous carcinoma, caprine.

Papillomaviruses (PVs), recently classified as Papillomaviridae family with different genera [1], are small, nonenveloped viruses which infect both humans and various animals from birds to mammals, usually causing benign proliferative epithelial lesions. Nevertheless, certain types of human PVs (HPVs), called "high-risk" or "oncogenic", such as HPV-16, HPV-18 and HPV-31, have been recognized as causative agents of cervical and anal cancers [2]. In addition, the involvement of bovine PV type 2 (BPV-2) in carcinogenesis of urinary bladder in cattle has also been demonstrated [3-5]. At the same time, it is becoming increasingly evident that other types of HPVs, particularly those belonging to genus beta, could be involved in nonmelanoma skin cancer, mainly squamous cell carcinoma (SCC), even though their putative etiologic role still remains unclear [6-9]. PVassociated basosquamous carcinoma has also been reported in an Egyptian fruit bat [10]; likewise, PV DNA sequences have been found in feline Bowenoid in situ carcinoma, a rare disease in cats that presents as multiple discrete plaques of epidermal hyperplasia and dysplasia [11]. Furthermore, current findings strongly support a potential active role of HPVs in the development of malignant melanoma [12-13]. As far as ocular tumours are concerned, they have also been aetiologically linked to PV infection both in humans and in cattle [14-17]. Recently, Van Doorslaer et al. [18] have determined the complete nucleotide sequence of Capra hircus PV-type 1 (ChPV-1), after amplification from healthy goat skin. However, PV-like DNA sequences have rarely been detected in caprine neoplasms [19], whereas they have not yet been identified in multiple coexisting tumours of such species.

In our study, we attempted to detect the presence of PV in multiple ocular and cutaneous neoplastic lesions spontaneously occurring in two adult Maltese twin goats, one male and one female, by means of immunohistochemical and

\footnotetext{
*Address correspondence to this author at the Regina Elena Cancer Institute, Laboratory of Virology, Via delle Messi d'Oro 156, 00158 Rome, Italy; Tel: +390652662520; Fax: +390652662505; E-mail: venuti@ifo.it

${ }_{\dagger}^{\dagger}$ These authors contributed equally as first authors to this work.

${ }^{\ddagger}$ These authors contributed equally as senior authors to this work.
}

biomolecular techniques. One year after the onset of ocular SCCs, which had been previously described [20], multiple cutaneous and additional ocular neoplasms were identified in both animals. Such tumours were histologically classified as multiple cutaneous fibropapillomas and SCCs (particularly located in periocular and perianal skin of both animals), one malignant melanoma of periocular skin, as well as one ocular fibrosarcoma. The immunohistochemical evaluation of paraffin-embedded tissue sections was carried out using a prediluted anti-PV polyclonal rabbit antibody (Ab) (Code No: N1547, Dako, Carpinteria, CA, USA), raised against chemically disrupted bovine PV-1 (BPV-1) and specifically reacting with L1 capsid protein of most known PVs (Dako specifications). Antigen retrieval was performed by heat-treating sections in citrate buffer at $\mathrm{pH} 6$ in a microwave oven for 15 min. Immune complexes were treated with secondary biotinylated Goat anti-Mouse\&Rabbit antibody (ready-to-use, Biospa, Milan, Italy) and subsequently were detected by a peroxidase-labelled polymer method (envision+ Dual Link System Peroxidase, Dako). Immunohistochemical results showed positive intranuclear (Fig. 1a, arrows) and perinuclear (Fig. 1a, arrowhead) staining for BPV-1 L1 antigen only in a few squamous cells within ocular SCC of female goat. We performed negative controls by omitting primary antibody (Fig. 1b) and by using irrelevant antibodies like polyclonal rabbit anti-human von Willebrand factor (Dako, Code n. A 0082) or polyclonal rabbit anti-human CD3 (Dako, Code n. 0452).

The very low number of positive cells may also explain the previous negative results on ocular neoplasms from the same animals [20].

Biomolecular studies were carried out by means of polymerase chain reaction (PCR), multiply-primed rollingcircle amplification (RCA), as well as in situ hybridisation (ISH).

Genomic DNA was extracted from formalin-fixed, paraffin-embedded tumour samples [21]. Ten microlitres of each samples were used as template for PCR amplification with the consensus primers MY09/MY11 that are able to amplify part of the L1 region of a large number of PV, as previously reported [20]. In all neoplastic tissue samples from both 

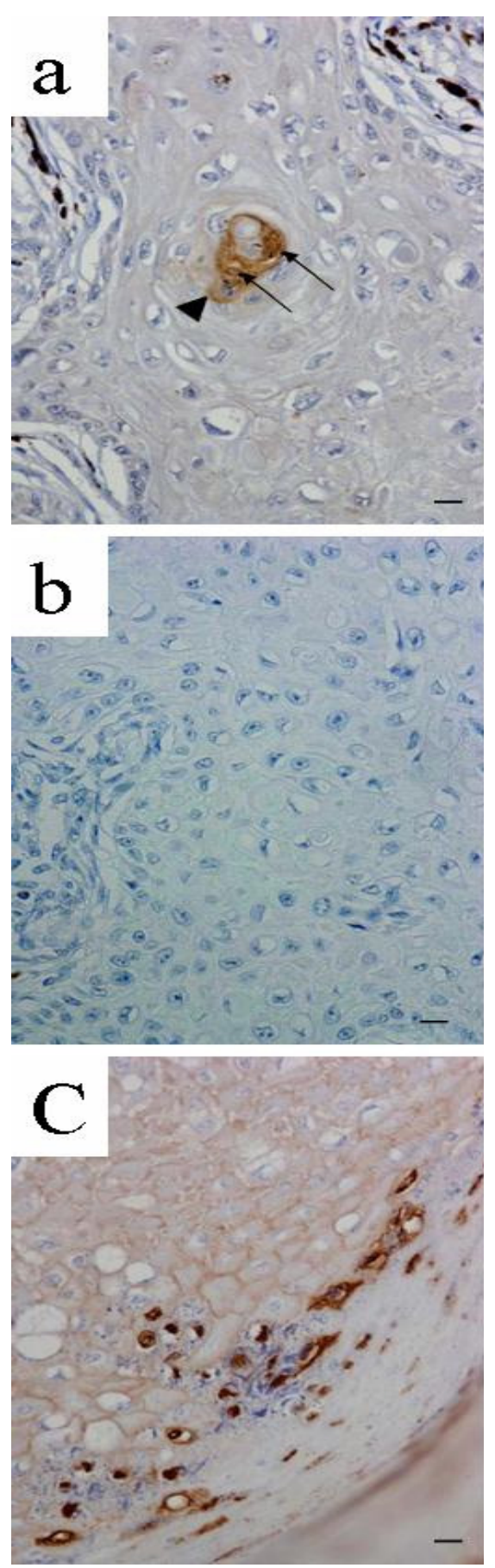

Fig. (1). Immunohistochemical staining for papillomavirus L1 capsid protein. Brown positive squamous cells within the ocular SCC (a). No stain within the ocular squamous cell carcinoma with the immuno-reaction lacking the primary antibody (b). Positive stain in the control tissue from a bovine wart (c). Scale bar $15 \mu \mathrm{m}$.

animals a product of the predicted length (450 bp) was detected in ethidium bromide-stained 3\% Nu-Sieve agarose gel. Direct sequencing of the fragment by an automated apparatus (Biogen srl., Rome, Italy) yielded sequences that were compared with those present in data bank by BLAST program (NCBI). A sequence homology ranging from 40 to $70 \%$ with some known papillomaviruses, including BPV-6, HPV6 and ChPV-1, was revealed.
In the region of the highest homology between our sequence and that of ChPV-1 [18] we designed two primers that allowed the amplification of a $237 \mathrm{bp}$ fragment (forward 5'-ACCCCAAAGCAAATTCAAATG-3'; reverse 5'- CTC AGCAACTATGTCTAAGC-3') (Fig. 2). This amplified product was detected in all the lesional samples and the analysis of the sequence (GenBank accession no. EU1675 50) confirmed a $82 \%$ homology in the L1 region of ChPV-1.

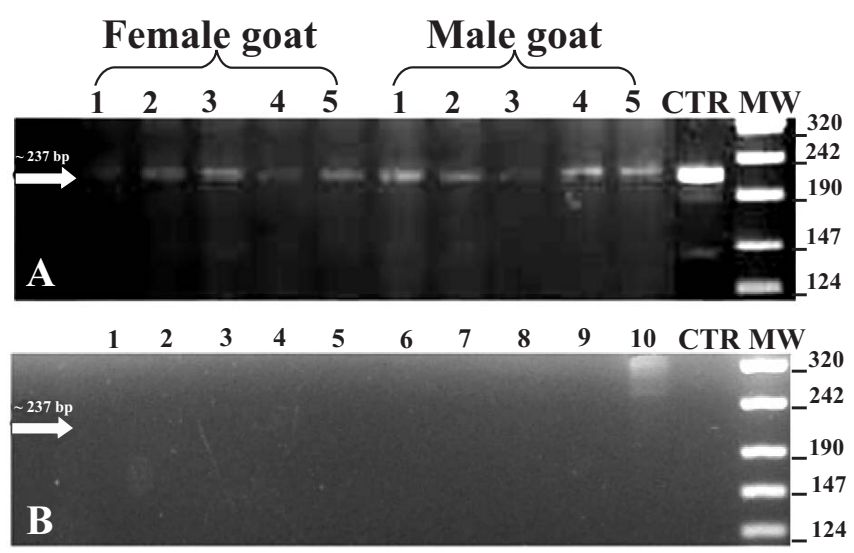

Fig. (2). Caprine papillomavirus DNA amplification.

Panel A. DNA samples from different areas and lesions (1-3 from ocular carcinomas; 4-5 from perianal warts) of twin goats was subjected to PCR amplification with specific primers as described in the text. An amplified product of approximately $237 \mathrm{bp}$ was detected in all the samples. Panel B. DNA samples from normal skin of other healthy goats (16) and from normal tissues of the female (7-8) and male (910) goat. Molecular weight marker (MW) type VIII (Roche Diagnostics, Germany), the numbers represent the band length in basepair (bp) CTR, positive control consisting of recombinant plasmid DNA from HPV-8 which shares homologies with the used primers. Same sequence was revealed from all the amplified products. This sequence was not detected in normal samples, demonstrating that they are from exogenous organism and not from goat genomic sequences (Fig. 2, Panel B).

In order to investigate the presence (and the sequence) of the entire genome of the papillomavirus under study and in the attempt to clone other sequences, the multiply-primed RCA reaction was performed using the TempliPhi 100 Amplification kit (Amersham Biosciences, Roosendaal, The Netherlands). In nature, replication of circular DNA molecules such as plasmids or viral genomes frequently occurs through a rolling circle mechanism. Rolling-circle amplification (RCA) is a novel technology mimicking this molecular amplification machinery. RCA has been used as a laboratory method for the amplification of small circular DNA templates via prolonged extension of exonuclease-resistant random hexamers. The method utilizes bacteriophage $\Phi 29$ DNA polymerase, a high-fidelity enzyme with a strong strand-displacing capability, high processivity and proofreading activity. By this method, we have already revealed the presence of episomal HPV-16 DNA in head and neck tumours [22]. Briefly, one $\mu \mathrm{g}$ of extracted DNA was transferred into a $0.2-\mathrm{ml}$ tube with $10 \mu \mathrm{l}$ of TempliPhi sample buffer, containing exonuclease-protected random hexamers. The samples were denatured at $95^{\circ} \mathrm{C}$ for $5 \mathrm{~min}$ and after- 
wards were placed on ice. A premix was prepared on ice by mixing, for each sample, $10 \mu 1$ of TempliPhi reaction buffer, containing salts and deoxynucleotides (dNTPs), and $1 \mu 1$ of TempliPhi enzyme mix, containing the $\Phi 29$ DNA polymerase and exonuclease-protected random hexamers in $50 \%$ glycerol and $450 \mu \mathrm{M}$ of extra dNTPs per sample. After mixing by vortexing, $5 \mu 1$ of premix was added to the cooled samples. The reaction mixtures were incubated overnight (approximately $16 \mathrm{~h}$ ) at $30^{\circ} \mathrm{C}$. Afterwards, the reaction mixtures were put on ice and subsequently heated to $65^{\circ} \mathrm{C}$ for 10 min to inactivate the $\Phi 29$ DNA polymerase.

All the RCA products were digested with the rare cutting enzymes EcoRI, HindIII and BamHI. Only the digestion with the BamHI demonstrated the presence of circular DNA sequences, compatible with the double-stranded circular DNA genome of Papillomaviruses. Unfortunately, the attempts to clone this sequence to obtain plasmids carrying the entire or a partial sequence of this putative PV genome failed. Such negative result may be explained by the low number of viral sequences. Indeed, semi-quantitative analysis by scanning densitometry of the PCR product in agarose gel indicated the presence of few copies of viral DNA per cell (data not shown). To localize the presence of this papillomavirus within the lesions ISH was performed on paraffinembedded tissue samples (Fig. 3).

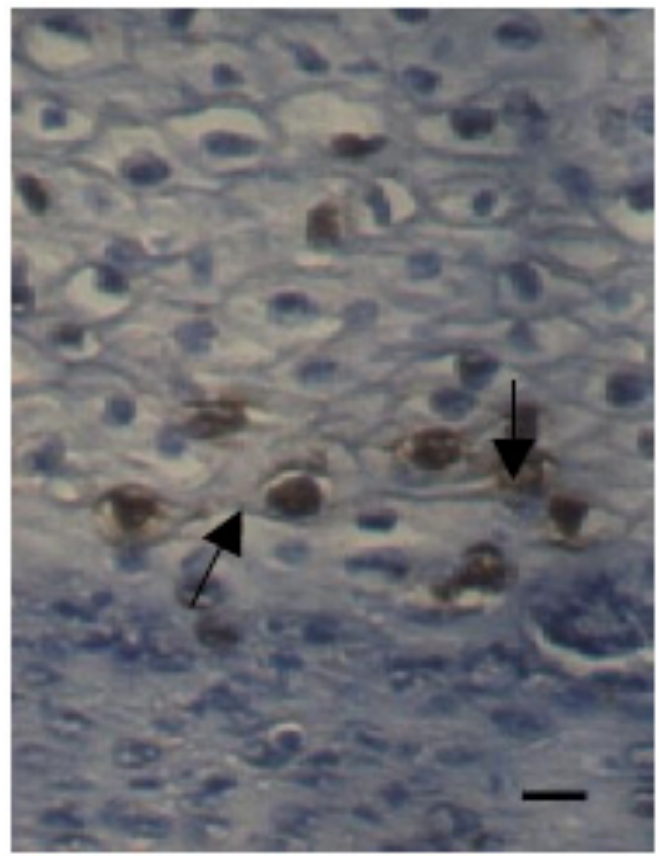

Fig. (3). In situ hybridization of perianal lesion of female goat.

Slides were counterstained with haematoxylin. The arrows indicate some positive nuclei with diffuse staining. Scale bar $10 \mu \mathrm{m}$

The probes were made with the amplified products labelled with biotin d-UTP. Each probe was hybridized on thin slices of samples previously treated with $\mathrm{H}_{2} \mathrm{O}_{2}$ in order to inactivate endogenous peroxidase. The hybridization was carried out at $37^{\circ} \mathrm{C}$ overnight in an hybridization mix containing $50 \%$ of formamide. After washings, the hybridization was revealed by a tyramide signal amplification system for biotinylated probes (GenPoint, Dako). The slides were counterstained with haematoxylin. ISH showed the presence of the amplified DNA sequences in the nucleus of some neoplastic cells and the diffuse staining of the nuclei indicated that PV sequences were in episomal form, confirming the RCA results.

Taken together, the above data clearly indicate the presence of PV DNA sequences, as well as focal L1 capsid protein expression within the nucleus of neoplastic cells in multiple cutaneous and ocular tumours of the twin goats under study. Despite the failure in isolating and sequencing the entire genome, the presence of episomal DNA, together with the expression of capsid protein, strongly suggest the possible presence of papillomavirus particles.

These findings open the question about a possible involvement of PV infection in the development of such malignancies in the caprine species. The amplified nucleotide sequence also appeared to be rather different from the recently characterized sequence data of ChPV-1 [18], thus suggesting the existence of various types of caprine PVs, which could be differently implicated in malignant transformation.

The potential oncogenic role of papillomaviruses is currently investigated in human skin cancer. However, the etiologic role of HPVs in skin cancer still remains poorly defined, since HPV DNA is also frequently detectable in healthy skin or plucked hairs from individuals with and without skin cancer [23-26]. In addition, a low copy number of HPV DNA is usually associated with skin cancer, thus suggesting that it could be contained only in a minority of tumour [7]. The data so far obtained are more compatible with cutaneous HPVs being possibly involved in tumour initiation and progression, with a so-called "hit and run" mechanism of carcinogenesis, as already demonstrated for the BPV-4-associated oesophageal carcinoma [27]. In this respect, our biomolecular and immunohistochemical findings, indicative of low levels of PV DNA sequences and viral antigens expression, are in agreement with such hypothesis.

PVs could act as cofactors of other established risk factors in skin carcinogenesis, such as sunlight exposure or immunosuppression [7]. In this respect, promoter stimulation of certain HPV types by ultraviolet (UV) radiation has also been described [28-30]. Finally, PV infection could also represent an auxiliary factor for development of skin cancer in genetic disorders, since an association between EV-HPV types and SCCs has been observed in young xeroderma pigmentosum patients, a rare autosomal recessive disease, characterized by deficient DNA repair and hypersensitivity to UV irradiation [31].

In conclusion, the present study represents the first report on PV-associated multiple cutaneous and ocular tumours in twin goats. Even though the etiopathogenetic role of PV infection remains undefined, a cooperation between the viral agent and genetic predisposition or environmental factors could be supposed. Along with the putative role played by a papillomaviral agent in the etiology of the different tumour lesions which were observed in the two goats under study, also their "gemellarity" condition should be adequately taken into account. As a matter of fact, the study of twins may be of value in cancer epidemiology since twins are genetically identical, or share half of their segregating genes; in this re- 
spect, while familial clustering has been observed for human neoplasms occurring at specific body sites, on one side, an increased risk of developing certain cancer types in man has been reported in monozygotic rather than in heterozygotic twins, on the other [32]. Nevertheless, further studies are needed to evaluate the prevalence of PV infection both in healthy and neoplastic goat skin. In addition, since detection of PV DNA in cancers could be a remnant of past viral activities or evidence of transient infections of tumors, it will be most important to evaluate type-specific immune response against early and late viral proteins as a reflection of viral activities over years [7]. Future investigations carried out both in humans and animals will probably contribute to clarify the role of PV infection in skin carcinogenesis.

\section{ACKNOWLEDGEMENT}

This work was supported by a grant of the Italian Ministry of Health.

\section{REFERENCES}

[1] de Villiers EM, Fauquet C, Broker TR, Bernard HU, zur Hausen H. Classification of papillomaviruses Virology 2004; 324: 17-27.

[2] Zheng Z, Baker CC. Papillomavirus genome structure, expression, and post-transcriptional regulation. Front Biosc 2006; 11: 22862302.

[3] Borzacchiello G, Iovane G, Marcante ML, et al. Presence of bovine papillomavirus type 2 DNA and expression of the viral oncoprotein E5 in naturally occurring urinary bladder tumours in cows. J Gen Virol 2003; 84: 2921-2926.

[4] Borzacchiello G, Russo V, Gentile F, et al. Bovine papillomavirus E5 oncoprotein binds to the activated form of the platelet-derived growth factor beta receptor in naturally occurring bovine urinary bladder tumours. Oncogene 2006; 23: 1251-1260.

[5] Borzacchiello G, Russo V, Spoleto C, et al. Bovine papillomavirus type-2 DNA and expression of E5 and E7 oncoproteins in vascular tumours of the urinary bladder in cattle. Cancer Lett 2007; 250: 8291.

[6] Masini C, Fuchs PG, Gabrielli F, et al. Evidence for the association of human papillomavirus infection and cutaneous squamous cell carcinoma in immunocompetent individuals. Arch Dermatol 2003; 139: $890-894$

[7] Pfister H. Chapter 8: human papillomavirus and skin cancer. J Natl Cancer Inst Monogr 2003; 31: 52-56.

[8] Harwood CA, Surentheran T, Sasieni P, et al. Increased risk of skin cancer associated with the presence of epidermodysplasia verruciformis human papillomavirus types in normal skin. Br J Dermatol 2004; 150: 949-957.

[9] Karagas MR, Nelson HH, Sehr P, et al. Human papillomavirus infection and incidence of squamous cell and basal cell carcinomas of the skin. J Natl Cancer Inst 2006; 98: 389-395.

[10] McKnight CA, Wise AG, Maes RK, et al. Papillomavirusassociated basosquamous carcinoma in an Egyptian fruit bat (Rousettus aegyptiacus). J Zoo Wildl Med 2006; 37: 193-196.

[11] Munday JS, Kiupel M, French AF, Howe L, Squires, RA. Detection of papillomaviral sequences in feline Bowenoid in situ carcinoma using consensus primers. J Vet Dermatol 2007; 18: 241-245.

[12] Ambretti S, Venturosi S, Mirasoli M, et al. Assessment of the presence of the mucosal human papillomaviruses in malignant melanomas using combined fluorescent in situ hybridisation and chemiluminescent immunohistochemistry. Br J Dermatol 2007; 156: 38-44.

[13] Rohwedder A, Slominski A, Wollf M, Kredentser D, Carlson JJ. Epidermodysplasia verruciformis and cutaneous human papillomavirus DNA, but not genital human papillomavirus DNAs, are frequently detected in vulvar and vaginal melanoma. Am J Dematopathol 2007; 29: 13-17.

[14] McDonnel JM, McDonnel JP, Sun YY. Human papillomavirus DNA in tissues and ocular surface swabs of patients with conjunctival epithelial neoplasia. Invest Ophthalmol Vis Sci 1992; 33: 184189.

[15] Nakamura Y, Mashima Y, Kameyama K, Mukai M, Oguchi Y Detection of human papillomavirus infection in squamous tumours of the conjunctiva and lacrimal sac by immunohistochemistry, in situ hybridisation, and polymerase chain reaction. Br J Ophthalmol 1997; 81: 308-313.

[16] Ford JN, Jennings PA, Spradbrow PB, Francis J. Evidence for papillomaviruses in ocular lesions in cattle. Res Vet Sci 1982; 32: 257-259.

[17] Rutten VP, Klein WR, De Jong MA, et al. Search for bovine papilloma virus DNA in bovine ocular squamous cell carcinomas (BOSCC) and BOSCC-derived cell lines. Am J Vet Res 1992; 53: 1477-1481.

[18] Van Doorslaer K, Rector A, Vos P, Van Ranst M. Genetic characterization of the Capra hircus papillomavirus: a novel close-to-root artiodactyl papillomavirus. Virus Res 2006; 118: 164-169.

[19] Manni V, Roperto F, Di Guardo G, Galati D, Condoleo RU, Venuti A. Presence of papillomavirus-like DNA sequences in cutaneous fibropapillomas of the goat udder. Vet Microbiol 1998; 61: 1-6.

[20] Marà M, Di Guardo G, Venuti A, et al. Spontaneous ocular squamous cell carcinoma in twin goats: pathological and biomolecular studies. J Comp Path 2005; 132: 96-100.

[21] Manos MM, Ting Y, Wright DK, Lewis AJ, Broker TR, Wolinsky $\mathrm{SM}$. Use of polymerase chain reaction amplification for the detection of genital human papillomavirus. Cancer Cells 1989; 7: 209214.

[22] Badaracco G, Rizzo C, Mafera B, et al. Molecular analyses and prognostic relevance of HPV in head and neck tumours. Oncol Rep 2007; 17: 931-939.

[23] Boxman IL, Berkhout RJ, Mulder LH, et al. Detection of human papillomavirus DNA in plucked hairs from renal transplant recipients and healthy volunteers. J Invest Dermatol 1997; 108: 712-715.

[24] Astori G, Lavergne D, Benton C, et al. Human papillomaviruses are commonly found in normal skin of immunocompetent hosts. J Invest Dermatol 1998; 110: 752-755.

[25] Wieland U, Ritzkowsky A, Stoltidis M, et al. Communication: papillomavirus DNA in basal cell carcinomas of immunocompetent patients: an accidental association? J Invest Dermatol 2000; 115 124-128.

[26] Meyer T, Arndt R, Christophers E, Nindl I, Stockfleth E. Importance of human papillomaviruses for the development of skin cancer. Cancer Detect Prev 2001; 25: 533-547.

[27] Campo MS, Moar MH, Sartirana ML, Kennedy IM, Jarrett WF. The presence of bovine papillomavirus type 4 DNA is not required for the progression to, or the maintenance of, the malignant state in cancers of the alimentary canal in cattle. EMBO J 1985; 4: 18191825.

[28] Purdie KJ, Pennington J, Proby CM, et al. The promoter of a novel human papillomavirus (HPV77) associated with skin cancer displays UV responsiveness, which is mediated through a consensus p53 binding sequence. EMBO J 1999; 18: 5359-5369.

[29] Ruhland A, de Villiers EM. Opposite regulation of the HPV 20URR and HPV 27-URR promoters by ultraviolet irradiation and cytokines. Int J Cancer 2001; 91: 828-834.

[30] Akgül B, Lemme W, Garcia-Escudero R, Storey A, Pfister. H J UV-B irradiation stimulates the promoter activity of the high-risk, cutaneous human papillomavirus 5 and 8 in primary keratinocytes. Arch Virol 2005; 150: 145-151.

[31] Luron L, Avril MF, Sarasin A, Daya-Grosiean L. Prevalence of human papillomavirus in skin tumors from repair deficient xeroderma pigmentosum patients. Cancer Lett 2007; 250: 213-219.

[32] Ahlbom A, Lichtenstein P, Malmström H, Feychting M, Hemminki $\mathrm{K}$, Pedersen ML. Cancer in twins: genetic and nongenetic risk factors. J Natl Cancer Inst 1997; 89: 287-293. 